\title{
Support for Altruistic Behavior in Rats
}

\author{
Shayna A. Wrighten, Chelsea R. Hall \\ Department of Biology, Francis Marion University, Florence, SC, USA \\ Email:swrighten@fmarion.edu
}

How to cite this paper: Wrighten, S.A. and Hall, C.R. (2016) Support for Altruistic Behavior in Rats. Open Journal of Social Sciences, 4, 93-102.

http://dx.doi.org/10.4236/jss.2016.412009

Received: November 19, 2016

Accepted: December 24, 2016

Published: December 27, 2016

Copyright $\odot 2016$ by authors and Scientific Research Publishing Inc. This work is licensed under the Creative Commons Attribution International License (CC BY 4.0).

http://creativecommons.org/licenses/by/4.0/

\begin{abstract}
Evidence for altruistic behaviors in rats has been continually building over many years, with a large surge in the past 10 years. Many researchers have posited that rats have the cognitive capabilities to engage in these altruistic behaviors that were at one time only attributed to species that are more complex. The results of many of the studies on altruistic behaviors in rats show parallels with non-human primate studies suggesting that what has been observed in rats is indeed altruism as it has been defined in primates. Research focused on rat altruism has provided evidence that these behaviors are influenced by familiarity, similar to findings among primates. Other evidence for altruistic behavior in rats is apparent in their ability to apply a costbenefit analysis when an opportunity to provide help is presented. There is also evidence that rats rely on previous experiences and predictions of future behaviors of others to make judgments when engaging in altruistic behaviors. Studies have also shown that rats exhibit these altruistic behaviors without the presence of a tangible reward, a primary component in the definition of altruism. The findings presented and the parallels with non-human primate studies provide good evidence that rats are capable of engaging in altruistic behaviors, and that rats may be good candidates for an alternative animal model for further studying altruism. Having rats as a valid model for the study of altruism opens the door to study facets of this behavior that otherwise would not be able to be studied. Because of the important contribution of altruism to social interactions, better understanding of this behavior will hopefully aid in positively influencing social societies such as those lived in by humans and other primates.
\end{abstract}

\section{Keywords}

Rodent Altruism, Pro-Social Behavior, Empathy, Helping Behavior, Rats

\section{Introduction}

Altruistic behavior has been extensively studied in human and non-human primates for 
many years. It is believed by some that altruistic behaviors are formed from complex patterns of cognitive function that occur only in social animals high on the phylogenetic tree. Evolutionarily, these behavioral patterns seem to likely have arisen as a means of increasing individual and/or group survival. For example, engaging in altruistic behaviors towards another individual is thought to make that individual more likely to reciprocate similar behaviors toward you in the future [1]-[7]. More simply put, if I help you when you are in need you are more likely to later help me when I am in need, thus causing my initial altruistic actions to at some point increase my chances of survival. Due to the complex nature of these behaviors, such as the potential underlying emotional motivator of empathy [8]-[13], many scientists have long held the belief that altruistic behaviors likely don't occur and therefore can't be studied in animals such as rats, who lack the cognitive capacity to experience and therefore express empathy through behavior [14] [15] [16] [17]. However, there is supporting evidence that rats do indeed have cognitive abilities sufficiently developed to exhibit behaviors of altruism. Not only do rats seem to carry out these behaviors, but evidence suggests that these occurrences are experience driven. This suggests that rats are cognitively capable of learning the necessary skills to carry out altruism in order to increase survival in social groups. If rats do indeed show altruistic behaviors in a manner similar to those carried out by human and non-human primates, rats can then be used as a model system to tease out nuances within the development and execution of these behaviors that can't be studied in primates. This article will provide a review of literature supporting evidence of altruism in rats. Throughout the review, parallels between primate and rodent studies of altruism will be highlighted to emphasize the similarities in behaviors and further support that what is seen in rats is altruism, as the behavior of altruism has been defined, and accepted as such, in primates.

\section{Support for Rodent Altruistic Behavior}

Altruism can be defined as "behavior of one animal that relieves another animal's distress" [18]. Although there have been a plethora of studies showing that rats engage in emotional contagion [19]-[26] these do not show behaviors of altruism that would align with the aforementioned definition. However, in 1962, Rice and Gainer published results suggesting that altruism is present in rats. In this experiment they showed that rats learned to press a lever to lower a suspended rat [18]. This article was met with some criticism, as in 1963 Lavery and Foley published work showing that rats learned to press a lever to lower a suspension that contained white noise or recorded rat squeals in the absence of a live rat [27]. These authors suggested that the lever pressing behavior of the rats were not acts of altruism, as indicated by Rice and Gainer the year prior [27]. Since rats pressed the lever even in the condition of white noise, Lavery and Foley argued that the rats in Rice and Gainer's article were not lever pressing out of altruism, but were instead showing reactionary increases in activity in response to an obnoxious stimulus (i.e. a squealing rat, [27]). Following the publication of these early studies there was a large hiatus in the study of rodent altruism. However, over the past ten 
years there has been a resurgence of interest in this field (for review: [11] [28] [29] [30] [31] [32]). With this resurgence has come additional evidence to support the premise that rats may not respond simply to arousal, as suggested by Lavery and Foley, but indeed show signs of altruism. In 2011, Bartal and colleagues showed that rats would learn to open a door, which freed a trapped cage mate from a restrainer [30]. Following up on these studies Bartal et al. showed that door opening behaviors were based on familiarity. Specifically, when placed in the paradigm with an unfamiliar rat of another strain, rats did not exhibit door-opening behavior [33]. However, when placed in the paradigm with familiar rats of a different strain (i.e. a rat from a different strain that was reared together with the potential helper rat) door opening behavior was carried out as was seen with the innately familiar strain [33]. These data show parallel with primate altruistic data, which show that direct relation and membership to the same social group positively influences altruistic behavior [34] [35] [36] [37]. Based on Lavery and Foley's argument that rats engaged in their behaviors in the Rice and Gainer experiments in order to avoid any type of unwanted stimulus or in response to increased activity that occurs by having an animal present, rats in the Bartal et al. paradigm should have opened the door in equal amounts for any rat without showing bias, which as Bartal and colleagues showed, was not the case. Recent findings from the Bartal lab suggest that these behaviors are dependent on the level of stress response exhibited by the helping rat. Specifically, rats were shown a trapped cage mate and corticosterone levels of the rat viewing the trapped cage mate were measured in order to assess hypothalamic-pituitary adrenal (HPA) axis activity. Rats who had higher HPA axis activity in response to viewing the trapped cage mate were faster at door opening for the trapped cage mate than rats who had less HPA activity in response to viewing a trapped cage mate [38]. Additionally, when non-trapped rats were given an anxiolytic drug prior to being placed in the paradigm, they were less likely to open the door for a cage mate than rats that did not receive the anxiolytic [38]. The authors take these pieces of data to suggest that the affective state of the helper rat must reflect the distress exhibited by the trapped rat in order for door opening behavior to occur.

Altruistic behavior in rats is further suggested by studies examining similar dooropening behaviors, but in a more stressful environment. Sato and colleagues showed that when placed in a pool of water, tenably a high stress situation for a rat, rats were more likely to engage in door opening behaviors to release the soaked conspecific than they were in the absence of water [31]. Interestingly, when the roles were reversed and the once soaked cage mate had the opportunity to reciprocate the altruistic favor, the now freed rat opened the door for his soaked cage mate at a much faster rate [31], suggesting that experience in a negative stressful situation increases altruistic behavior; a pattern also observed in primates [39]. Furthermore, Silberberg and colleagues found that rats will "rescue" a cage mate, a behavior they attributed to desire for social contact [40]. Silberberg and colleagues used a paradigm similar to that used by Bartal and colleagues, but modified the restrainer door so that it could be opened by the press of a touch sensor on its outside [40]. 
Further support that these behaviors do indeed represent altruism is found in the lack of tangible reward received by the rat in response to door opening behavior. Opening the restrainer door allows a cage mate to be free, but does not produce any type of apparent extrinsic reward, such as food, for the door opener. One could argue that the ability for the helper rat to be able to interact with the rat that was helped is a tangible reward. However, Bartal and colleagues have shown that even when a partition is placed inhibiting interaction between rats once the restrainer door is opened, the free rat will still open the restrainer door for the trapped cage mate in the same manner as when the partition is not present [30], though the role of contact between rats as a motivating factor in this behaviour is debated [40]. Although there may be an extrinsic reward received by the altruistic rat that has yet to be discerned, the studies presented to date imply that the rat engaging in the freeing behaviors gains no personal reward. This lack of tangible reward would align these rodent behaviors with the definition of altruism in which an individual helps another without the necessity of gaining an immediate physical reward. This is not to imply there is no reward gained when an altruistic act is carried out, a reward such as personal satisfaction may be enough to induce altruistic behavior, but this potential is still being debated in human and other primates as well [41] [42].

It is interesting to note that there is a cost-benefit relationship apparent in rodent altruism. In studies performed by Schneeberger and others, rats were not willing to engage in a task that provided food to a conspecific if the means to do so was beyond a certain level of difficulty [43]. However, if the rat to receive the food was mildly food deprived, the rat displaying altruistic behavior would provide its partner with food despite the cost/difficulty associated with doing so [43]. Schneeberger and colleagues suggest that these behaviors indicate that rats are able to evaluate the need of a social partner and react accordingly. Two different mechanisms were proposed as means for the observed rats to evaluate the need of their partner. The first mechanism proposed is that the rat in need gives off some sort of signal, such as ultrasonic vocalization, indicating its need for help. The second mechanism proposed is the detection of unseen physical indicators by the helping rat, such as breath odor. This study may provide some insight into a potential mechanism underlying altruism that surrounds perpetuation of the species. Similar findings have been reported showing a negative correlation between body weight and likelihood of food reward being provided [44]. More specifically, if a partner rat is of a lower weight, the helper rat is more likely to provide it with food. This correlation may imply that the helper rat detects a lower body weight (or some other indicator) that may signify malnourishment in the partner rat. Providing help and therefore offsetting the chances of mortality helps the species in an evolutionarily responsible way. Cost to benefit ratios have also been shown to determine likelihood of primate altruistic behavior [1] [4] [5] [6] [11] [45] [46].

It has been argued that these paradigms using rats, in particular that used by the Bartal group, do not show altruistic behavior but instead show behavior that evolutionarily would be important to continue the species by increasing reproductive success of 
a conspecific [47]. More specifically, the altruistic rat shows helping behavior in order to support an individual who could possibly be a reproductive mate thereby increasing his/her (the altruistic rat) fitness. However, in the studies that have thus far been carried out rats placed in the paradigms are of the same sex, which should eliminate increased reproductive success as a motivating factor. This is especially true, because the studies to date have focused on altruistic behavior primarily in male rats. If the speculation of Vasconcelos and colleagues is true, then the rats should not help its conspecific because helping, and evolutionarily speaking potentially increasing survival of, another male would introduce increased reproductive competition for self. However, if reproduction does somehow play a role in rodent altruism that would agree with primate altruism, as it is thought by some that altruism is never a purely selfless act, but one that in some way enhances inclusive fitness [48] [49] [50].

An important aspect of altruism is that of reciprocity. It has been argued by Zentall that cooperative altruism, altruism carried out in response to being the prior recipient of altruistic behavior, does not occur in rats [51]. It could be argued that the cognitive processing required to engage in behavior as complicated as cooperative altruism is beyond the capacity of rats. Specifically, to engage in cooperative altruism one must use prior experience to make decisions about current actions. Additionally, the individual would need to be able to at least in part base this decision on how he thinks the individual to be helped will behave in the future. Thus, prior to engaging in cooperative altruistic behaviors the individual, in this case a rat, would need to answer the questions 1) has this other individual helped me previously and 2) is this other individual likely to help me in the future. There is evidence to suggest that rats do indeed make decisions that suggest cooperative altruism partly, if not fully, carried out based on answers to these questions.

In 2007, Rutte and Taborsky reported that rats exhibit cooperative behaviors impacted by social experience. In their paradigm, rats that had previously been helped by another rat were $21 \%$ more likely to help a rat than those who had previously not been helped [28] [43]. Not only are rats more likely to help others if they themselves have been helped, but also show altruism based on the type of help they have received. In a study by Dolivo and Taborsky, if a rat was provided with a food of high preference by a conspecific, that rat was more likely to provide food for another in the future and would do so at a faster rate than if the altruistic rat had previously been provided a less preferable food choice by a conspecific [52]. These data suggest that rats engage in reciprocal altruistic behavior and that these behaviors are at least in part based on prior experience. Furthermore, in a more complex design, rats showed an ability to engage in difficult cognitive decisions based on prior experience and on future expectations. The paradigm used a double T-maze separated by a transparent perforated wall. Each maze had a start box with independent doors connected to two decision chambers of the maze. In this paradigm, two rats were placed in the start box and the first rat (actor) was allowed to choose which box to enter. Next, the second rat (partner) was allowed to enter a chamber (in the connected T-maze) based on where the experimenter led it. If 
both of the rats were in the reward box, they both received a food reward. If the partner rat was in the reward box and the actor (rat making the choice of which box to enter) was in the punishment box, the partner received a reward and the actor received a punishment (tail pinch). If both rats were in the punishment box, they both received the punishment. In this design rats could deliver a reward to self and partner, punishment to self and partner, or reward to self and punishment to partner [53]. The actor rats adapted their behavior based on the behavior of the opponent. When the behavior of the partner rat was unpredictable, the actor rat was more likely to choose a punishment box, which would more likely result in a reward for self but not for other [53]. However, when the move of the partner rat occurred in a predictable pattern the actor rat showed more responses that aligned with tit-for-tat [53]. In this somewhat complex paradigm, the rats had to adapt their behavior not only based on the past experience, but also had to use those past experiences to predict what future behaviors their counterpart was most likely to engage in. The role of past experience and prediction of future actions in carrying out altruistic behavior is one that is also seen in primates, both human [54] [55] and non-human [16] [22] [37] [56].

It has been shown that not only do rats engage in altruistic behavior but that they prefer helping another opposed to helping self only [44] [57]. In the Hernandez-Lallament et al. paradigm one rat (partner) was placed in a box. Another rat (actor) was given the choice of entering a box that would result in food for self-only or food for self and partner. When given this choice rats were more likely to enter the box that resulted in food for both self and other [44]. This behavior was absent in the presence of a toy rat indicating that the actor rat selected the "both reward" box to provide food for a conspecific opposed to some other stimulus such as novelty of the box. The actor rat received the same reward regardless of which box was chosen. Therefore, the most plausible motivation for choosing a reward for both was so that the partner could receive a reward. Further studies by this group show that this behavior is heavily dependent on activation and function of the basolateral amygdala. Following lesion of the basolateral amygdala rats were less likely to choose to reward both self and partner compared to sham operated rats [58]. Basolateral amygdala lesion did not show effects on reward preference, the rats still showed a preference for having access to a larger versus smaller reward; these data imply that proper basolateral amygdala function is paramount in the decision making process for mutual reward preferences.

\section{Conclusion}

Overall, multiple studies have provided evidence that rats engage in behaviors that in primate studies would be considered altruism. Altruistic behavior in rats seems to occur despite evidence of a tangible reward. Furthermore, these behaviors are seen in reciprocate conditions, which requires a higher level of cognitive analysis than was previously thought to be capable by rats. Many questions still remain in this field such as additional neural pathways and hormonal mechanisms underlying these behaviors, how these behaviors are affected by age, the role of genetic background in rat altruism, 
the effect of environmental factors on altruism and much more. However, the information that has been gained thus far provides a foundation for acquiring a better understanding to altruism, and supporting the use of rats to study aspects of altruism that are hard to study in primates.

\section{References}

[1] Trivers, R.L. (1971) The Evolution of Reciprocal Altruism. Quarterly Review of Biology, 46, 35-57. https://doi.org/10.1086/406755

[2] Seyfarth, R.M. and Cheney, D.L. (1984) Grooming, Alliances and Reciprocal Altruism in Vervet Monkeys. Nature, 308, 541-543. https://doi.org/10.1038/308541a0

[3] Brosnan, S.F. and De Waal, F.B. (2002) A Proximate Perspective on Reciprocal Altruism. Human Nature, 13, 129-152. https://doi.org/10.1007/s12110-002-1017-2

[4] de Waal, F.B. and Brosnan, S.F. (2006) Simple and Complex Reciprocity in Primates. In: Cooperation in Primates and Humans, Springer Berlin Heidelberg, 85-105. https://doi.org/10.1007/3-540-28277-7_5

[5] Schino, G. (2007) Grooming and Agonistic support: A Meta-Analysis of Primate Reciprocal Altruism. Behavioral Ecology, 18, 115-120. https://doi.org/10.1093/beheco/arl045

[6] de Waal, F.B. and Suchak, M. (2010)Prosocial Primates: Selfish and Unselfish Motivations. Philosophical Transactions of the Royal Society of London B: Biological Sciences, 365, 2711-2722. https://doi.org/10.1098/rstb.2010.0119

[7] Jaeggi, A.V., De Groot, E., Stevens, J.M. and Van Schaik, C.P. (2013) Mechanisms of Reciprocity in Primates: Testing for Short-Term Contingency of Grooming and Food Sharing in Bonobos and Chimpanzees. Evolution and Human Behavior, 34, 69-77. https://doi.org/10.1016/j.evolhumbehav.2012.09.005

[8] Preston, S.D. and De Waal, F.B. (2002) Empathy: Its Ultimate and Proximate Bases. Behavioral and Brain Sciences, 25, 1-20.

[9] Decety, J. and Jackson, P.L. (2004) The Functional Architecture of Human Empathy. Behavioral and Cognitive Neuroscience Reviews, 3, 71-100. https://doi.org/10.1177/1534582304267187

[10] de Vignemont, F. and Singer, T. (2006) The Empathic Brain: How, When and Why? Trends in Cognitive Sciences, 10, 435-441. https://doi.org/10.1016/j.tics.2006.08.008

[11] De Waal, F.B. (2008) Putting the Altruism Back into Altruism: The Evolution of Empathy. Annual Review of Psychology, 59, 279-300. https://doi.org/10.1146/annurev.psych.59.103006.093625

[12] Decety, J. (2010) The Neurodevelopment of Empathy in Humans. Developmental Neuroscience, 32, 257-267. https://doi.org/10.1159/000317771

[13] Decety, J. (2015) The Neural Pathways, Development and Functions of Empathy. Current Opinion in Behavioral Sciences, 3, 1-6. https://doi.org/10.1016/j.cobeha.2014.12.001

[14] Stevens, J.R. and Hauser, M.D. (2004) Why Be Nice? Psychological Constraints on the Evolution of Cooperation. Trends in Cognitive Sciences, 8, 60-65. https://doi.org/10.1016/j.tics.2003.12.003

[15] Penn, D.C. and Povinelli, D.J. (2007) On the Lack of Evidence That Non-Human Animals Possess Anything Remotely Resembling a "Theory of Mind". Philosophical Transactions of the Royal Society of London B: Biological Sciences, 362, 731-744. https://doi.org/10.1098/rstb.2006.2023 
[16] De Waal, F.B. and Ferrari, P.F. (2010) Towards a Bottom-Up Perspective on Animal and Human Cognition. Trends in Cognitive Sciences, 14, 201-207. https://doi.org/10.1016/j.tics.2010.03.003

[17] Vasconcelos, M., Hollis, K., Nowbahari, E. and Kacelnik, A. (2012) Pro-Sociality without Empathy. Biology Letters, 8, 910-912. https://doi.org/10.1098/rsbl.2012.0554

[18] Rice, G.E. and Gainer, P. (1962) “Altruism” in the Albino Rat. Journal of comparative and physiological psychology, 55, 123-125. https://doi.org/10.1037/h0042276

[19] Langford, D.J., Crager, S.E., Shehzad, Z., Smith, S.B., Sotocinal, S.G., Levenstadt, J.S., Mogil, J.S., et al. (2006) Social Modulation of Pain as Evidence for Empathy in Mice. Science, 312, 1967-1970. https://doi.org/10.1126/science.1128322

[20] Knapska, E., Mikosz, M., Werka, T. and Maren, S. (2010) Social Modulation of Learning in Rats. Learning \& memory, 17, 35-42. https://doi.org/10.1101/lm.1670910

[21] Bruchey, A.K., Jones, C.E. and Monfils, M.H. (2010) Fear Conditioning By-Proxy: Social Transmission of Fear during Memory Retrieval. Behavioural Brain Research, 214, 80-84. https://doi.org/10.1016/j.bbr.2010.04.047

[22] Atsak, P., Orre, M., Bakker, P., Cerliani, L., Roozendaal, B., Gazzola, V., Keysers, C., et al. (2011) Experience Modulates Vicarious Freezing in Rats: A Model for Empathy. PLoS ONE, 6, e21855. https://doi.org/10.1371/journal.pone.0021855

[23] Mogil, J.S. (2012) The Surprising Empathic Abilities of Rodents. Trends in Cognitive Sciences, 16, 143-144. https://doi.org/10.1016/j.tics.2011.12.012

[24] Akyazi, I. and Eraslan, E. (2014) Transmission of Stress between Cagemates: A Study in Rats. Physiology \& Behavior, 123, 114-118. https://doi.org/10.1016/j.physbeh.2013.10.006

[25] Martin, L.J., Tuttle, A.H. and Mogil, J.S. (2014) The Interaction between Pain and Social Behavior in Humans and Rodents. In: Taylor, B.K. and Finn, D.P., Eds., Behavioral Neurobiology of Chronic Pain, Springer, Berlin, 233-250. https://doi.org/10.1007/7854_2014_287

[26] Mogil, J.S. (2015) Social Modulation of and by Pain in Humans and Rodents. Pain, 156, S35-S41. https://doi.org/10.1097/01.j.pain.0000460341.62094.77

[27] Lavery, J.J. and Foley, P.J. (1963) Altruism or Arousal in the Rat? Science, 140, 172-173. https://doi.org/10.1126/science.140.3563.172

[28] Rutte, C. and Taborsky, M. (2007) Generalized Reciprocity in Rats. PLOS Biology, 5, e196. https://doi.org/10.1371/journal.pbio.0050196

[29] Rutte, C. and Taborsky, M. (2008) The Influence of Social Experience on Cooperative Behavior of Rats (Rattus norvegicus): Direct Vsgeneralised Reciprocity. Behavioral Ecology and Sociobiology, 62, 499-505. https://doi.org/10.1007/s00265-007-0474-3

[30] Bartal, I.B.A., Decety, J. and Mason, P. (2011) Empathy and Pro-Social Behavior in Rats. Science, 334, 1427-1430. https://doi.org/10.1126/science.1210789

[31] Sato, N., Tan, L., Tate, K. and Okada, M. (2015) Rats Demonstrate Helping Behavior toward a Soaked Conspecific. Animal cognition, 18, 1039-1047. https://doi.org/10.1007/s10071-015-0872-2

[32] Panksepp, J. (2011) Empathy and the Laws of Affect. Science, 334, 1358-1359. https://doi.org/10.1126/science.1216480

[33] Bartal, I.B.A., Rodgers, D.A., Sarria, M.S.B., Decety, J. and Mason, P. (2014) Pro-Social Behavior in Rats Is Modulated by Social Experience. eLife, 3, e01385.

[34] Cronin, K.A. (2012) Prosocial Behavior in Animals: The Influence of Social Relationships, Communication and Rewards. Animal Behaviour, 84, 1085-1093.

https://doi.org/10.1016/j.anbehav.2012.08.009 
[35] Silk, J.B., Brosnan, S.F., Vonk, J., Henrich, J., Povinelli, D.J., Richardson, A.S., Schapiro, S.J., et al. (2005) Chimpanzees Are Indifferent to the Welfare of Unrelated Group Members. Nature, 437, 1357-1359. https://doi.org/10.1038/nature04243

[36] Vonk, J., Brosnan, S.F., Silk, J.B., Henrich, J., Richardson, A.S., Lambeth, S.P., Povinelli, D.J., et al. (2008) Chimpanzees Do Not Take Advantage of Very Low Cost Opportunities to Deliver Food to Unrelated Group Members. Animal Behaviour, 75, 1757-1770. https://doi.org/10.1016/j.anbehav.2007.09.036

[37] Schino, G. and Aureli, F. (2009) Reciprocal Altruism in Primates: Partner Choice, Cognition, and Emotions. Advances in the Study of Behavior, 39, 45-69. https://doi.org/10.1016/S0065-3454(09)39002-6

[38] Bartal, I.B.A., Shan, H., Molasky, N., Murray, T., Williams, J., Decety, J. and Mason, P. (2016) Anxiolytic Treatment Impairs Helping Behavior in Rats. bioRxiv, Article ID: 044180.

[39] De Waal, F.B., Aureli, F. and Judge, P.G. (2000) Coping with Crowding. Scientific American, 282, 76-81. https://doi.org/10.1038/scientificamerican0500-76

[40] Silberberg, A., Allouch, C., Sandfort, S., Kearns, D., Karpel, H. and Slotnick, B. (2014) Desire for Social Contact, Not Empathy, May Explain "Rescue" Behavior in Rats. Animal cognition, 17, 609-618. https://doi.org/10.1007/s10071-013-0692-1

[41] De Waal, F.B., Leimgruber, K. and Greenberg, A.R. (2008) Giving Is Self-Rewarding for Monkeys. Proceedings of the National Academy of Sciences, 105, 13685-13689. https://doi.org/10.1073/pnas.0807060105

[42] Warneken, F. (2013) The Development of Altruistic Behavior: Helping in Children and Chimpanzees. Social Research: An International Quarterly, 80, 431-442.

[43] Schneeberger, K., Dietz, M. and Taborsky, M. (2012) Reciprocal Cooperation between Unrelated Rats Depends on Cost to Donor and Benefit to Recipient. BMC Evolutionary Biolo$g y, 12,41$. https://doi.org/10.1186/1471-2148-12-41

[44] Hernandez-Lallement, J., van Wingerden, M., Marx, C., Srejic, M. and Kalenscher, T. (2015) Rats Prefer Mutual Rewards in a Prosocial Choice Task. Frontiers in Neuroscience, 8, 443. https://doi.org/10.3389/fnins.2014.00443

[45] Jensen, K., Hare, B., Call, J. and Tomasello, M. (2006) What's in It for Me? Self-Regard Precludes Altruism and Spite in Chimpanzees. Proceedings of the Royal Society of London B: Biological Sciences, 273, 1013-1021. https://doi.org/10.1098/rspb.2005.3417

[46] Nowak, M.A. (2006) Five Rules for the Evolution of Cooperation. Science, 314, 1560-1563. https://doi.org/10.1126/science.1133755

[47] Barnes, J.L., Hill, T., Langer, M., Martinez, M. and Santos, L.R. (2008) Helping Behavior and Regard for Others in Capuchin Monkeys (Cebus apella). Biology Letters, 4, 638-640. https://doi.org/10.1098/rsbl.2008.0410

[48] Porter, R.H. and Laney, M.D. (1980) Attachment Theory and the Concept of Inclusive Fitness. Merrill-Palmer Quarterly of Behavior and Development, 26, 35-51.

[49] Griffin, A.S. and West, S.A. (2003) Kin Discrimination and the Benefit of Helping in Cooperatively Breeding Vertebrates. Science, 302, 624-636. https://doi.org/10.1126/science.1089402

[50] West, S.A., Griffin, A.S. and Gardner, A. (2007) Evolutionary Explanations for Cooperation. Current Biology, 17, R661-R672. https://doi.org/10.1016/j.cub.2007.06.004

[51] Zentall, T.R. (2015) Reciprocal Altruism in Rats: Why Does It Occur? Learning \& Behavior, 44, 7-8. https://doi.org/10.3758/s13420-015-0201-2

[52] Dolivo, V. and Taborsky, M. (2015) Norway Rats Reciprocate Help According to the Qual- 
ity of Help They Received. Biology Letters, 11, Article ID: 20140959.

https://doi.org/10.1098/rsbl.2014.0959

[53] Viana, D.S., Gordo, I., Sucena, E. and Moita, M.A. (2010) Cognitive and Motivational Requirements for the Emergence of Cooperation in a Rat Social Game. PLoS ONE, 5, e8483. https://doi.org/10.1371/journal.pone.0008483

[54] Thompson, C., Barresi, J. and Moore, C. (1997) The Development of Future-Oriented Prudence and Altruism in Preschoolers. Cognitive Development, 12, 199-212. https://doi.org/10.1016/S0885-2014(97)90013-7

[55] Fehr, E. and Fischbacher, U. (2003) The Nature of Human Altruism. Nature, 425, 785-791. https://doi.org/10.1038/nature02043

[56] Brothers, L. (2002) The Social Brain: A Project for Integrating Primate Behavior and Neurophysiology in a New Domain. In: Cacioppo, J.T., Ed., Foundations in Social Neuroscience, MIT Press, Cambridge, 367-385.

[57] Márquez, C., Rennie, S.M., Costa, D.F. and Moita, M.A. (2015) Prosocial Choice in Rats Depends on Food-Seeking Behavior Displayed by Recipients. Current Biology, 25, 17361745. https://doi.org/10.1016/j.cub.2015.05.018

[58] Hernandez-Lallament, J., van Wingerden, M. and Schäble, S. (2016) Basolateral Amygdala Lesions Abolish Mutual Reward Preferences in Rats. Neurobiology of Learning and Memory, 127, 1-9. https://doi.org/10.1016/j.nlm.2015.11.004

Submit or recommend next manuscript to SCIRP and we will provide best service for you:

Accepting pre-submission inquiries through Email, Facebook, LinkedIn, Twitter, etc. A wide selection of journals (inclusive of 9 subjects, more than 200 journals)

Providing 24-hour high-quality service

User-friendly online submission system

Fair and swift peer-review system

Efficient typesetting and proofreading procedure

Display of the result of downloads and visits, as well as the number of cited articles

Maximum dissemination of your research work

Submit your manuscript at: http://papersubmission.scirp.org/

Or contact jss@scirp.org 